\title{
Association of Acid-Base Balance in the Renal Proximal Tubule and Blood Pressure Alterations: Potential Role of Local Mediators
}

\author{
Dinesh Aryal, Keith E. Jackson* \\ School of Basic Pharmaceutical and Toxicological Sciences, College of Pharmacy, University of Louisiana at Monroe, Monroe, LA, \\ USA \\ Email: *kjackson@ulm.edu
}

How to cite this paper: Aryal, D. and Jackson, K.E. (2020) Association of Acid-Base Balance in the Renal Proximal Tubule and Blood Pressure Alterations: Potential Role of Local Mediators. Journal of Biosciences and Medicines, 8, 26-44.

https://doi.org/10.4236/jbm.2020.84003

Received: February 22, 2020

Accepted: March 29, 2020

Published: April 2, 2020

Copyright $\odot 2020$ by author(s) and Scientific Research Publishing Inc. This work is licensed under the Creative Commons Attribution International License (CC BY 4.0).

http://creativecommons.org/licenses/by/4.0/

\begin{abstract}
Disturbances in acid-base balance leading to the development of hypertension are currently gaining increased attention among researchers. Perturb acid-base balance characterized by metabolic acidosis has been demonstrated in hypertensive animals and humans. Research suggests that acid-base changes are not only the consequences of elevated blood pressure but can precede the development of hypertension. However, no exact mechanism has been identified to link acid-base imbalance with alterations in blood pressure. The kidney proximal tubule is the major site for maintaining normal bicarbonate concentrations which is an important component of acid-base balance. Acid-base transporter proteins in the renal proximal tubule such as $\mathrm{Na}^{+} / \mathrm{HCO}_{3}^{-}$ cotransporters, $\mathrm{Na}^{+} / \mathrm{H}^{+}$exchangers, and anion-exchangers play important roles in controlling acid secretion, ammonia production and bicarbonate reabsorption for maintaining acid-base balance. It is well known that sodium retention in the renal tubules leads to increase in blood volume and consequently increases in blood pressure. Therefore, it is the purpose of this review to discuss the role of sodium-coupled acid-base transporters in regulating proximal tubular sodium retention and controlling blood pressure homeostasis. We will also focus on the capacity of local mediators; angiotensin II, cortisol, prostaglandin and aldosterone, to regulate acid-base and blood pressure homeostasis.
\end{abstract}

\section{Keywords}

Acid-Base Transporters, Hypertension, Proximal Tubule, Angiotensin II

\section{Introduction}

The kidney plays a crucial role in maintaining acid-base homeostasis, which is 
important for proper functioning of several physiological processes in the body. The kidneys also regulate extracellular fluid volume (ECFV) homeostasis by controlling sodium and water balance, which is a key component of blood pressure control [1]. Kidneys have two significant roles in maintaining acid-base balance; namely, they reabsorb bicarbonate from urine and excrete hydrogen ions in the form of ammonium into urine. The association of bicarbonates and hydrogen ions with sodium-linked transporter proteins such as $\mathrm{Na}^{+} / \mathrm{HCO}_{3}^{-}$ cotransporters, $\mathrm{Na}^{+} / \mathrm{H}^{+}$exchangers, and anion-exchangers plays a significant role in both acid-base balance and blood pressure regulation [2]. Since the proximal tubule is the major site for sodium reabsorption in the kidney, it is the purpose of this review to examine the current literature in regards to the relationship between acid-base imbalance and hypertension as well as to explore the possible biological pathways underlying the linkage between these health conditions.

The renin-Angiotensin Aldosterone System (RAS) has been widely studied for its role in the pathogenesis of hypertension and associated renal injury. In recent years, focus has been shifted to the importance of tissue specific local RAS components and their activation, contributing to the regulation of renal hemodynamics, maintenance of extracellular fluid volume, regulation of sodium reabsorption and the control of blood pressure [3]. In the kidney, angiotensin II (Ang II) is one of the components of the RAS system compartmentalized in the renal interstitial fluid and the proximal tubular (PT) compartments with much higher concentrations than those existing in the systemic circulation [4]. Local Ang II signaling in the kidney regulates acid-base transport and metabolism [5]. Under acidic conditions, proximal tubule cells upregulate the expression of type 1 Ang II receptors, hence enhancing the ammonia genesis action of Ang II to counter the acid-base imbalance [6]. Since, intrarenal Ang II signaling via AT1a receptors in the renal proximal tubule is a major regulator of blood pressure and sodium homeostasis [7], the increasing effect of Ang II during acid challenge might have a significant role in sodium homeostasis. No studies to date have provided a clear insight upon the independent role of Ang II inside the tubule cell to lead to disturbed acid-base balance and affect blood pressure regulation. This review will explore the effect of disturbed acid-base balance in the proximal tubule that may eventually contribute to the pathogenesis of increased blood pressure. The focus will be on the potential role of local mediators like Ang II.

Endogenous elevations of angiotensin II could stimulate several pathophysiological mechanisms, which contribute to hypertension. Recent studies show that, chronically elevated Ang II augments sympathetic nerve outflow directly, probably by inhibiting the reflex decrease in sympathetic nerve activity following an increase in arterial pressure [8]. Involvement of reactive oxygen species (ROS) as second messengers in Ang II-mediated signaling in the CNS could be the novel signaling mechanism important in hypertension triggered by Ang II acting in the CNS [9]. Inflammation has recently emerged as an important mechanism in 
the progression of Ang II-dependent hypertension [10]. Intrarenal Ang II has been studied for its role in altering proximal tubule sodium $\left(\mathrm{Na}^{+}\right)$transport, which consequently affects blood pressure homeostasis [11] [12].

It is well documented that renal $\mathrm{Na}^{+}$retention leads to hypertension. Acid-base transporters in the renal tubules play a significant role in mediating renal $\mathrm{Na}^{+}$retention as most of the acid-base transporters are coupled with $\mathrm{Na}^{+}$. Hence there might exist a direct linkage between acid-base balance and the mechanism involved in hypertension which needs to be further elucidated [13]. Over the last few decades, several investigators including genetic based studies have proposed that alterations in the expression and function of acid-base transporters can be involved in blood pressure deregulation [14] [15]. In one of the studies, oral administration of sodium bicarbonate containing mineral water for seven days to hypertensive subjects resulted in a decreased systolic blood pressure (by 5 $\mathrm{mmHg}$ ). Similarly, in some salt-sensitive, but not in salt-resistant patients, oral loading with sodium bicarbonate $\left(\mathrm{NaHCO}_{3}\right)$ increases blood pressure, but the pressor effect of $\mathrm{NaHCO}_{3}$ is half that of sodium chloride $(\mathrm{NaCl})$ [16]. These alterations in blood pressure regulation have been demonstrated genetically in several animal models with disrupted expression of acid-base transporters. The human SLC4A5 gene encoding $\mathrm{NBCe} 2\left(\mathrm{Na}^{+} / \mathrm{HCO}_{3}^{-}\right.$-cotransporter $)$has been identified as a hypertensive susceptible gene based on the association of a single nucleotide polymorphisms with blood pressure (BP) levels and hypertension status [17]. However, controversy still exists as to the exact functional characteristics and within which section of renal tubule leads to hypertension.

\section{Acid-Base Transport in Renal Proximal Tubule: Role of Ang II}

The renal proximal tubule (RPT) is a mutual site for acid-base transport, which promotes regulation of blood $\mathrm{pH}$ as well as sodium and water transport to maintain renal fluid dynamics. The ability of RPT acid-base transporters to affect blood pressure regulation has been hypothesized [18]. In this light acid-base transporters are expressed in all segments of the nephron and collecting duct; and since the actions of many acid-base transporters involve co- or counter-transport of $\mathrm{Na}^{+}$and/or $\mathrm{Cl}^{-}$, they can directly influence renal $\mathrm{NaCl}$ handling and eventually pressure natriuresis [19]. Few would argue the importance of pressure natriuresis in the regulation of normal blood pressure.

The kidneys have the predominant role of regulating systemic bicarbonate $\left(\mathrm{HCO}_{3}^{-}\right.$) concentration and hence, the metabolic components of acid-base balance. This function of the kidneys has two components: reabsorption of virtually all the filtered $\mathrm{HCO}_{3}^{-}$and production of new $\mathrm{HCO}_{3}^{-}$to replace that consumed by normal or pathologic acids. This production or generation of new $\mathrm{HCO}_{3}^{-}$is done by net acid excretion. Net acid excretion by the kidneys occurs by two processes: the excretion of titratable acid and the excretion of ammonium $\left(\mathrm{NH}_{4}^{+}\right)$[20]. We briefly summarize in this review, the ammonia excretion from 
proximal tubule and its effect on sodium bicarbonate reabsorption.

Interstitial angiotensin II stimulates $\mathrm{H}^{+}$secretion and $\mathrm{HCO}_{3}^{-}$reabsorption in both proximal and distal tubules. In proximal tubules, Ang II at low concentrations $\left(<10^{-9} \mathrm{M}\right)$ stimulate bicarbonate reabsorption, $\mathrm{Na}^{+} / \mathrm{H}^{+}$-exchange, and $\mathrm{Na}^{+} / \mathrm{HCO}_{3}^{-}$cotransport, while inhibition of bicarbonate reabsorption has been documented with concentrations higher than $10^{-8} \mathrm{M}$ [21]. A study on human subjects claimed that Ang II regulates acid-base balance, as administration of Losartan (AT1 blocker) exacerbates acidosis by significantly decreasing net acid excretion [22]. However, there are not enough studies to corroborate whether the above mentioned action of Ang II is via a renal mechanism. Nagami, 2004 confirmed that Ang II stimulates ammonia production and secretion at the S3 segments of proximal tubule in acidotic mice [23]. Ang II receptors are present both on the luminal and the basolateral membranes of the proximal tubule. Acid secretion, bicarbonate reabsorption and ammonia production are stimulated by Ang II binding to either luminal or basolateral membrane receptors. However, to promote ammonia secretion, the Ang II must bind with luminal membrane receptors. This site-specific activity of Ang II may regulate the other sodium-linked transporters that are present on the membrane of the PT which ultimately can influence the concentration of sodium and fluid volume inside the cell [7] [24].

In this review, we will briefly summarize the potential role of acid-base transporters mainly, $\mathrm{Na}^{+} / \mathrm{H}^{+}$-exchanger (NHE3), $\mathrm{Na}^{+} / \mathrm{HCO}_{3}^{-}$cotransporters (NBCe1, $\mathrm{NBCe} 2, \mathrm{NBCn} 1), \mathrm{Cl}^{-} / \mathrm{HCO}_{3}^{-}$-exchanger and $\mathrm{Na}^{+} / \mathrm{K}^{+}$ATPase pump on alterations in blood pressure (Figure 1). We will also discuss the role of intrarenal angiotensin II in acid-base transport across the proximal tubule leading to blood pressure disturbances.

\section{1. $\mathrm{Na}^{+} / \mathrm{H}^{+}$Exchanger}

The $\mathrm{Na}^{+} / \mathrm{H}^{+}$Exchanger is a transporter present mostly on the apical side of the proximal tubule which functions to secret $\mathrm{H}^{+}$in exchange for $\mathrm{Na}^{+}$promoting regulation of acid-base homeostasis. NHE3 is the major isoform of this transporter which is encoded by the SLC9A3 gene [25]. The proximal tubule reabsorbs at least $70 \%-80 \%$ of the approximately $4500 \mathrm{mEq} / \mathrm{d}$ of filtered $\mathrm{HCO}_{3}^{-}$. Most (probably $>70 \%$ ) of this $\mathrm{HCO}_{3}^{-}$reabsorption is stimulated by $\mathrm{H}^{+}$secretion on the apical membrane by the sodium-hydrogen exchanger (NHE3). In addition to reabsorption of filtered $\mathrm{HCO}_{3}^{-}$, the kidneys also produce additional $\mathrm{HCO}_{3}^{-}$beyond that which has been filtered at the glomerulus. This process occurs by the excretion of acid into the urine. The net acid excretion of the kidneys is quantitatively equivalent to the amount of $\mathrm{HCO}_{3}^{-}$generation by the kidneys [20] [26] [27]. Previous studies have shown; blood pressure is lower in renal NHE3-deficient than in wild type mice on a normal sodium chloride diet but is normalized when fed a high sodium chloride diet [28]. This suggests that cellular $\mathrm{H}^{+}$secretion plays a potential role in the observed dietary blood pressure lowering effects. In addition, angiotensin II increases luminal $\mathrm{H}^{+}$secretion in exchange for 


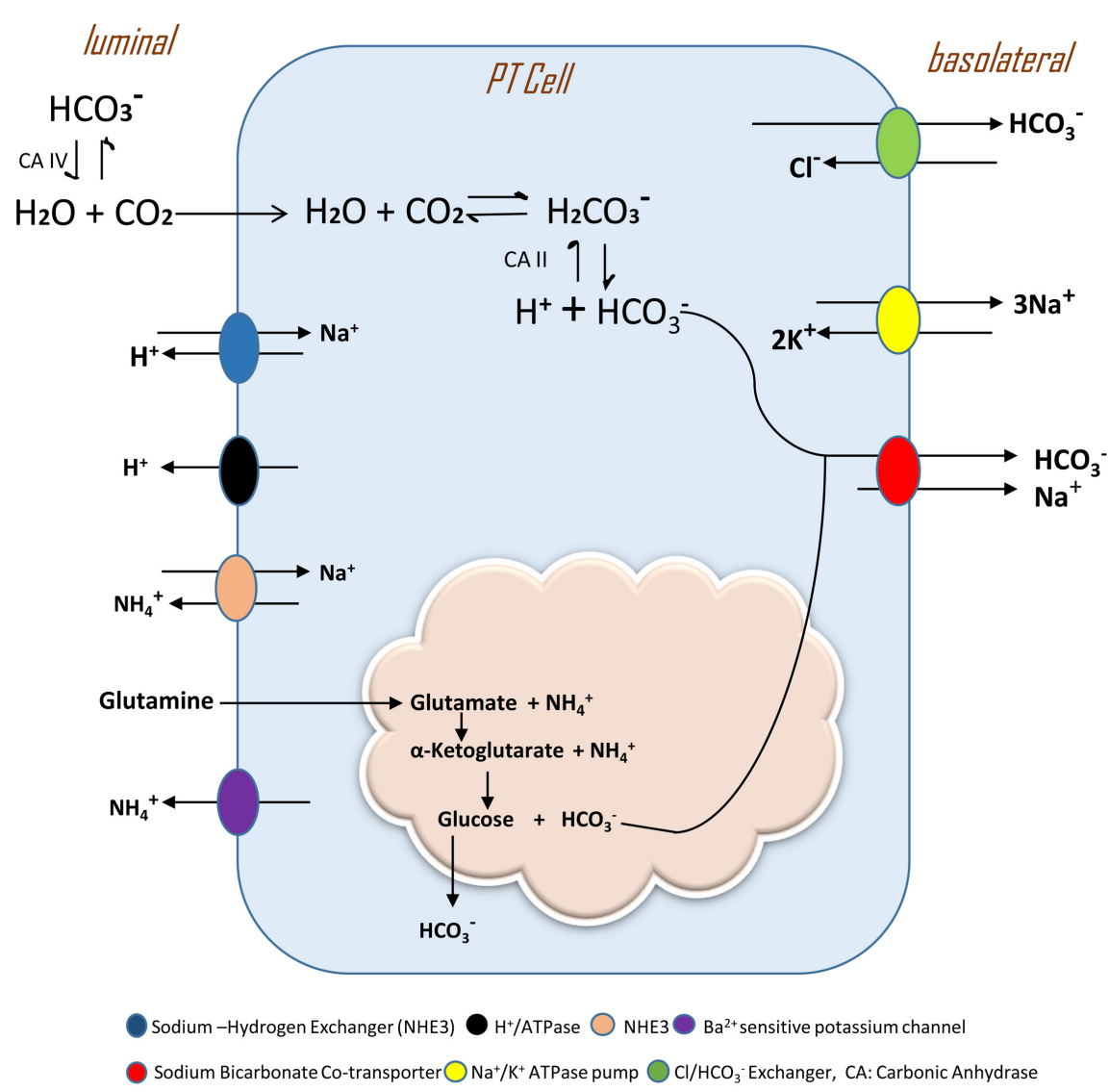

Figure 1. Sodium transport, bicarbonate reabsorption and ammonia metabolism across proximal tubule.

$\mathrm{Na}^{+}$into the cell via AT1 receptors because it does not affect the exchange in AT1R knockout mice and renal proximal tubule cells in which the AT1R is blocked or silenced. This provides evidence for intrarenal angiotensin II mediated NHE3 activity [29].

\section{2. $\mathrm{Na}^{+} / \mathrm{HCO}_{3}^{-}$Cotransporter}

Proximal tubule cells in the kidney transport $\mathrm{HCO}_{3}^{-}$into the interstitial fluid and ultimately to the blood, mainly via the renal splice variant of the electrogenic $\mathrm{Na}^{+} / \mathrm{HCO}_{3}^{-}$co-transporter NBCe1-A; however, other isoforms namely, NBCe2 and $\mathrm{NBCn} 1$ are also present [30]. NBCe1-A is located on the basolateral membrane of $\mathrm{PT}$ cells and is responsible for $3 \mathrm{HCO}_{3}^{-}$ions transport into the blood for each $\mathrm{Na}^{+}$ion whereas, $\mathrm{NBCe} 2$ is present mostly on the luminal membrane of the proximal tubule [31]. In the collecting duct, mutation in the SLC4A5 gene encoding NBCe2 induces hypertension because of the stimulation of $1: 1 \mathrm{Na}^{+}$to $\mathrm{HCO}_{3}^{-}$stoichiometry of other transporters like $\mathrm{NBCn} 1$ rather than the 1:2 stoichiometry of the NBCe2. Therefore, for every $\mathrm{HCO}_{3}^{-}$reabsorption there is equal $\mathrm{Na}^{+}$reabsorption from $\mathrm{NBCn} 1$ as compare to $\mathrm{NBCe} 1-\mathrm{A}$, which ultimately results in blood pressure elevation [32]. However, in case of the proximal tubule, $\mathrm{NBCe} 2$ is present on the apical membrane so there may be 
some other transporters activated, which could promote $\mathrm{Na}^{+}$reabsorption. Another study showed an increase in NBCe1-A expression reported in the renal cortex of spontaneously hypertensive rats as compared to Wistar Kyoto rats [33]. However, it is unclear whether these changes in acid-base transporter expression and function are causative, compensatory or unrelated to the blood pressure alterations. It is well observed that AT1 receptors are expressed in renal PT cells and regulate the uptake of local Ang II, therefore local Ang II may control the NBCe1-A and NBCe2 independently, while maintaining normal bicarbonate concentrations and $\mathrm{Na}^{+}$homeostasis. Ang II has the greatest stimulatory effect on the reabsorption rate of $\mathrm{HCO}_{3}^{-}$when applied at a low dosage to either the luminal or the basolateral surface (Figure 2). When applied at a high dosage to either surface, however, Ang II reduces $\mathrm{HCO}_{3}^{-}$reabsorption [34] [35]. The stimulatory effects of Ang II on $\mathrm{HCO}_{3}^{-}$reabsorption may be mediated by a decrease in intracellular cyclic AMP levels or by activating a PKC pathway [36] [37]. Taken together, there is need of further research to explore the role of acid-base transporters on activation of local mediators influencing the blood pressure homeostasis.

\section{3. $\mathrm{Cl}^{-} / \mathrm{HCO}_{3}^{-}$Exchanger}

Among human bicarbonate transporters, two major gene families encode $\mathrm{Na}^{+}$ independent $\mathrm{Cl}^{-} / \mathrm{HCO}_{3}^{-}$exchangers: the SLC4 anion exchanger (AE) family, and the SLC26 "sulfate permease" anion transporter family. The most extensively studied among them are the $\mathrm{Na}^{+}$-independent anion exchangers, AE1, AE2, and AE3, all of which are expressed in the kidney [38] [39]. $\mathrm{HCO}_{3}^{-}$generated intracellularly exits the basolateral membrane through a chloride-bicarbonate exchanger, a truncated version of the anion exchanger 1 (AE1), which is the

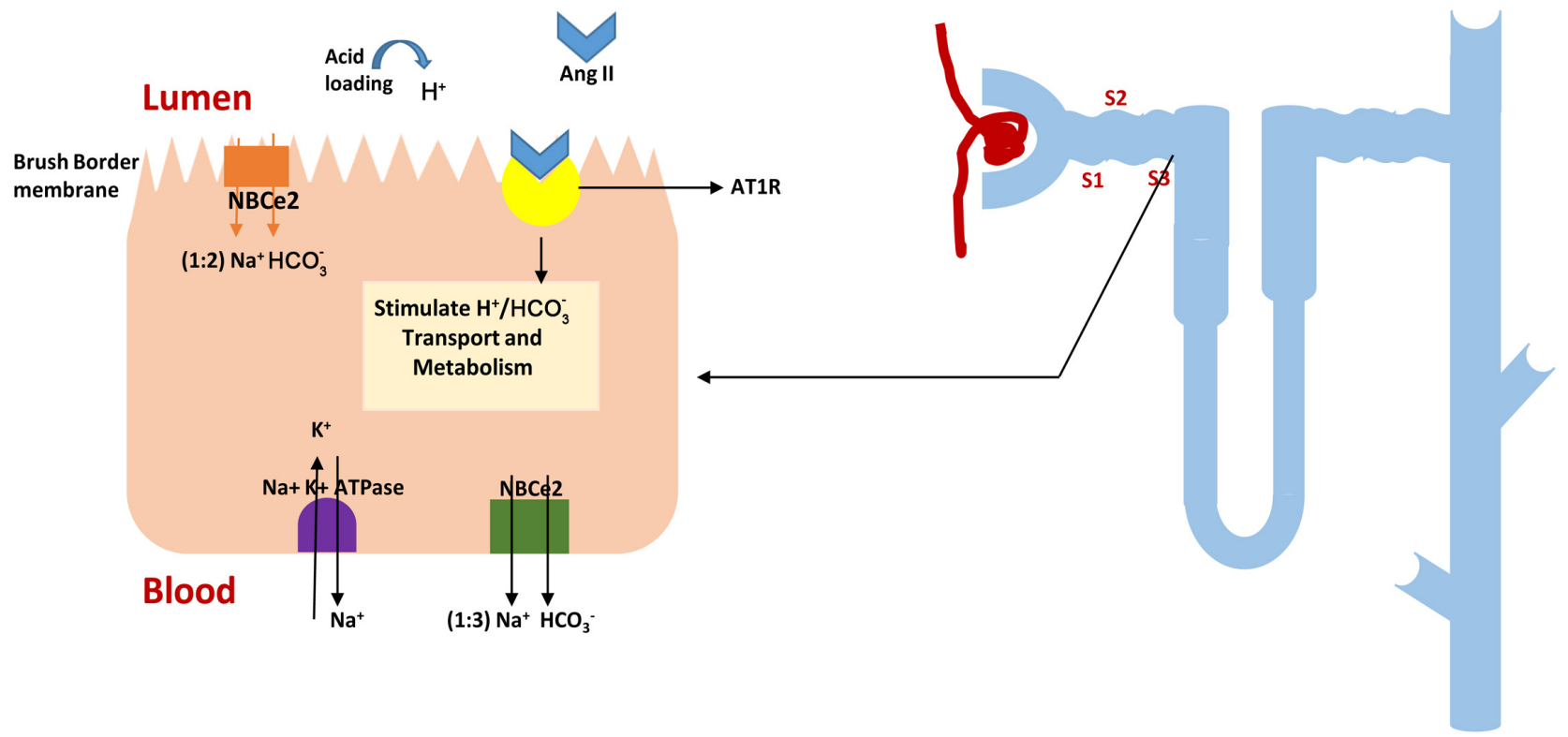

Figure 2. Angiotensin II regulated sodium-bicarbonate transport across S3 segment of renal proximal tubule cell in nephron. 
$\mathrm{Cl}^{-} / \mathrm{HCO}_{3}^{-}$exchanger in red blood cells that facilitates $\mathrm{CO}_{2}$ transport [40]. The $\mathrm{Cl}^{-} / \mathrm{HCO}_{3}^{-}$exchanger is stimulated by oxidative stress and by $\alpha 1$-adrenoceptors in immortalized proximal tubular epithelial cells of spontaneous hypertensive rats [41]. Angiotensin II also increases $\mathrm{Cl}^{-} / \mathrm{HCO}_{3}^{-}$exchanger activity in immortalized renal proximal tubules from spontaneous hypertensive rats as compared to proximal tubules from normotensive WKY rats [42]. Furthermore, bicarbonate reabsorption is independent of the presence of luminal chloride in isolated rabbit medullary collecting duct, although it is completely abolished in the absence of basolateral chloride, presumably due to impairment of peritubular bicarbonate exit in exchange for $\mathrm{Cl}^{-}$via the $\mathrm{Cl}^{-} / \mathrm{HCO}_{3}^{-}$exchanger AE1 [43].

\section{4. $\mathrm{Na}^{+} / \mathrm{K}^{+}$ATPase Pump}

$\mathrm{Na}^{+} / \mathrm{K}^{+}$ATPase pumps are active transporters, which are localized mostly on the basolateral side of proximal convoluted tubules second only to distal convoluted tubules [44]. The major role of these pumps is to balance the concentration of $\mathrm{Na}^{+}$and $\mathrm{K}^{+}$on the tubular and luminal sites of nephrons. These pumps function by ATP mediated transport of three sodium ions out of cells for two potassium ions into cells, both against their concentration gradients [45]. Although, less has been explored about the role of $\mathrm{Na}^{+} / \mathrm{K}^{+}$pump in acid-base balance, $\mathrm{Na}^{+} / \mathrm{K}^{+}$ATPase stimulates several other $\mathrm{Na}^{+}$-dependent cotransporters such as Na-glucose, Na-phosphate, Na-amino acids and exchangers like $\mathrm{Na}^{+} / \mathrm{H}^{+}$on the luminal membrane. One such active transporter is the $\mathrm{H}^{+} / \mathrm{K}^{+}$ATPase, which is expressed in the renal tubules, where it may function in potassium reabsorption and in the maintenance of acid-base balance [46]. Overexpression of $\mathrm{Na}^{+} / \mathrm{K}^{+}$ATPase transporters in the renal proximal tubule of hypertensive rats in previous studies has been identified. The overexpression of $\mathrm{Na}^{+} / \mathrm{K}^{+}$ATPases was regulated by local hormones like Ang II and aldosterone [47]. Ang II acutely stimulates $\mathrm{Na}^{+} / \mathrm{K}^{+}$ pump expression in plasma membranes of rat proximal tubules by approximately $33 \%$. Phosphorylation at the Ser 938 residue of the $\mathrm{Na}^{+} / \mathrm{K}^{+}$ATPase is responsible for the overexpression of the pump [48]. Also, Ang II stimulates the renal proximal tubule $\mathrm{Na}^{+} / \mathrm{K}^{+}$ATPase activity via activation of Protein Kinase $\mathrm{C}$ (PKC) [49]. In contrast, Ang II activates NADPH oxidase which inhibits the activity of the $\mathrm{Na}^{+} / \mathrm{K}^{+}$pump in cardiac myocytes via a PKC dependent pathway [50]. Furthermore, aldosterone increases $\mathrm{Na}^{+} / \mathrm{K}^{+}$ATPase activity in the proximal tubule via classical mineralocorticoid receptor activation [51]. Prostaglandins role in renal ion-transport has been previously shown. An acute study showed that one of its isoform PGE1, when incubated with rabbit kidney PT cells, increases the expression of $\mathrm{Na}^{+} / \mathrm{K}^{+}$ATPase [52]. These results provide the mechanistic insight for involvement of $\mathrm{Na}^{+} / \mathrm{K}^{+}$ATPase pump for controlling other transporter proteins for regulating acid-base balance along with maintaining blood pressure.

\section{Ammonia Transport in Renal Proximal Tubule}

Renal ammonia metabolism is crucial for maintaining acid-base balance. In the 
proximal tubule, ammonium $\left(\mathrm{NH}_{4}^{+}\right)$is generated from glutamine. Glutamine is first converted to glutamate by glutaminase. Then glutamate dehydrogenase converts glutamate to $\alpha$-ketoglutarate and two ammonium ions. The $\alpha$-ketoglutarate can be oxidized or converted to glucose (which is used for gluconeogenesis), both processes release bicarbonate. The ammonium is transported into the renal lumen in exchange for sodium by a luminal exchanger. The ammonium is then excreted into the urine with filtered chloride as its anion. The bicarbonate is returned to the blood via the basolateral sodium/bicarbonate cotransporter. This process generates new bicarbonate, while excreting an acid (ammonium chloride). Hypokalemia and acidemia stimulate ammonia genesis, promoting hydrogen excretion and bicarbonate retention [53]. Angiotensin II stimulates the basolateral sodium/bicarbonate cotransporter, facilitating absorption of the generated bicarbonate. In the proximal tubules, ammonia generation is linked to sodium absorption. Hence, increased ammonia production may stimulate sodium reabsorption and volume expansion, which could ultimately lead to rise in blood pressure. Ammonia production and transport are regulated by a variety of factors, including extracellular $\mathrm{pH}$ and potassium $\left(\mathrm{K}^{+}\right)$concentration, and by several hormones, such as mineralocorticoids, glucocorticoids and angiotensin II. This coordinated process of regulated ammonia production and transport is critical for the effective maintenance of acid-base homeostasis. Ang II stimulates ammonia production and secretion in proximal tubule segments through intracellular calcium-mediated signaling. In contrast, a concentration-dependent effect of angiotensin II on total ammonia production in the proximal tubule of the micro-perfused mouse was observed. The ammonia genesis is stimulated in lower concentration ranges but inhibited at high concentrations. The increased intracellular calcium mediates the stimulatory effect of angiotensin II [54] [55] [56] [57].

During metabolic acidosis, Ang II stimulates the ammonia genesis and secretion of ammonia from the proximal convoluted tubules with an upregulation of NHE3 transporters on the brush border membrane [58]. Current literature supports the involvement of $\mathrm{Rh}$ glycoproteins in the transport of ammonia. Chronic metabolic acidosis in animals was shown to increase basolateral plasma membrane Rhcg expression [59]. These critical facilitators of ammonia transport in the kidney could mark a new approach for studying the mechanism of ammonia transport and its consequence on acid-base homeostasis, which ultimately affects blood pressure regulation.

\section{Disturbed Acid-Base Balance and Its Consequences on Renovascular Function}

Metabolic acidosis can be the common cause of disturbing acid-base balance which is characterized by decreased blood $\mathrm{pH}$ because of a reduction in bicarbonate reabsorption and acid accumulation in the blood. The excessive consumption of acid precursor foods (mainly sources of phosphorus and proteins) 
commonly associated with a western-type diet may lead to a chronic imbalance in acid-base regulation eventually resulting in cardio-metabolic dysfunction. Metabolic acidosis is known to cause insulin resistance in the skeletal muscle [60] [61]. The acute form of metabolic acidosis has a profound effect on kidney function, promoting a progress decline in the Glomerular Filtration Rate (GFR) [62]. However, there are only a few studies investigating the molecular pathway of acidosis related hypertension, and whether acidemia can induce local mediators promoting hypertension remains unclear. One of those studies suggests, chronic metabolic acidosis may stimulate intrarenal renin-angiotensin system components (i.e., Angiotensinogen, Ang II, Angiotensin Converting Enzyme) along with proteinurea, which is a marker of kidney injury [63]. Hence, more studies are required to confirm the association of acid loading with the activation of a vasoconstrictor like Ang II in renal tubules, which could ultimately be responsible for promoting hypertension.

Furthermore, the impact of intracellular acid-base disturbances on the contractile and relaxant functions of the arterioles has been studied for its effect on hypertension. As hypertension is characterized by increased contraction of the vascular wall, an increase in intracellular acid load has been associated with an ability to induce contraction of vascular smooth muscle cells [64] [65]. A decrease in intracellular $\mathrm{pH}$ via acid loading in vascular smooth muscle cells causes contractions, and during the contraction, an acid-base transporter $\mathrm{NBCn} 1$ is activated in a calcineurin-dependent pathway leading to an increase in intracellular $\mathrm{Ca}^{2+}$ [66] [67]. Hence, the acid-base imbalance activates $\mathrm{Ca}^{2+}$ signaling in vascular smooth cells and may have an important role in the pathogenesis of increased peripheral resistance in the arteries. Although, this review focuses on renal mechanism of blood pressure regulation during altered acid-base balance, the above described studies cannot be disregarded for its potential mechanism whereby acid-base imbalance leads to sustained hypertension. Since, the exact mechanism of essential hypertension remains to be elucidated, one cannot rule out the possibility of diet induced alterations in acid-base balance leading to activation of local mediators, such as angiotensin II or prostaglandins, which activate cellular pathways, such as calcineurin-dependent pathways, or PKC dependent pathways to increase sodium reabsorption and volume expansion which consequently promote hypertension.

\section{Possible Renal Mechanisms Linking Metabolic Acidosis and Increased Blood Pressure}

\subsection{Insulin Resistance}

Insulin resistance is a pathological condition characterized by impaired response to insulin stimulation in target tissues i.e., liver, muscle and adipose tissues [68]. Apart from these classical insulin target tissues, insulin receptors are also expressed in kidney tubules and arterial vasculature. In the vasculature, insulin acts via phosphoinositide-3-kinase (PI3K) pathway to produce NO and hence dilate 
the vessels. During impaired insulin function (insulin resistance), the vasodilator action is impeded, consequently rising the blood pressure. On the other hand, insulin action upon renal tubular sodium reabsorption is preserved during insulin resistance hence contributing to reduce natriuresis and rise in blood pressure [69] [70].

DeFronzo et al., initially observed that disturbed acid-base balance could develop insulin resistance in humans [71]. Also, correction of the acid-base imbalance, improves insulin resistance in patient with chronic kidney disease [72]. A recent study inferred that, reduced insulin receptor expression during insulin resistance in renal proximal tubule give rise to the development of albuminuria which is markedly higher in hypertensive individuals [73] [74]. Angiotensin II plays an important role in regulating insulin signaling by blocking insulin mediated NO production and promoting vasoconstriction via MAPK pathway [75]. These studies suggest that impact of disturbed acid-base balance in renal tubules could alter insulin signaling which might play a role in pathogenesis of hypertension. Further studies are needed to explore various acid-base transporters in renal tubular compartment and their effect on insulin resistance-mediated rise in blood pressure.

\subsection{Aldosterone Secretion}

Acidosis induced aldosterone secretion is unique in that it doesn't follow classical biosynthesis methods involving increase plasma potassium levels, adrenocorticotropic hormone (ACTH) stimulation and angiotensin II activation. However, plasma hydrogen ion concentration could be the regulator of aldosterone secretion during metabolic acidosis [22] [76] [77]. Genetic mutation of gene, CYP11B2 encoding aldosterone synthase (an enzyme responsible for biosynthesis of aldosterone) has produced low blood pressure effect and metabolic acidosis in human subjects [78]. Therefore, there might exist an independent mechanism which interlink the metabolic acidosis-induced aldosterone secretion and blood pressure regulation. Less has been studied of the effect of aldosterone on proximal tubule, as mostly aldosterone act via mineralocorticoid receptors predominantly expressed in distal convoluted tubules and collecting tubules of nephron, which promotes $\mathrm{Na}^{+}$retention and increases blood volume ultimately increasing the blood pressure [79]. However, some studies conferred that aldosterone inhibits urinary ammonium excretion by impairing ammonia genesis in the proximal tubule cellular compartments [80]. Further studies can be designed to see the independent effect of aldosterone on various sodium linked acid-base transporters in the proximal tubules and its consequences on sodium homeostasis leading to blood pressure regulation.

\subsection{Cortisol Production}

A study showed, diet induced mild metabolic acidosis could lead to rise in blood pressure possibly by the increase production of cortisol by adrenal cortex [81]. 
The primary mechanism behind this cortisol-induced hypertension is the overstimulation of the non-selective mineralocorticoid receptors abundant in distal convoluted tubules and the collecting ducts of the nephron which results in $\mathrm{Na}+$ reabsorption, volume expansion and finally rise in blood pressure [82]. However, during systemin acidosis, the rise in production of cortisol promotes, ammonium excretion, increase titratable acid production and increase proximal tubule $\mathrm{Na}^{+} / \mathrm{H}^{+}$exchange [83]. Hence, cortisol mediated physiological alterations in acid-base transporters and ammonia metabolism could be the novel mechanism yet to be explored to support the acidosis-induced hypertension. Cortisol has demonstrated variable effects on renin-angiotensin system. The renin substrate (angiotensinogen) maybe increase during cortisol stimulation but no significant change in plasma Ang II concentration has been observed. Hence, systemic Ang II is less likely to be a part of mechanism involved in cortisol induced hypertension [84]. Whether, the activation of local renin angiotensin system in metabolic acidosis-induced cortisol production must be addressed before conferring the RAS independent effect of cortisol in hypertension.

\subsection{Heme Oxygenase Induction}

Heme Oxygenase $(\mathrm{HO})$ is an enzyme that degrades heme to free iron, biliverdin and carbon mono-oxide (CO) [85]. HO-1 is stress induce isoform of $\mathrm{HO}$, concentrated mostly in spleen, liver and kidneys [86]. Researchers have reported that, disturbed acid-base physiology during metabolic acidosis is associated with increased expression of HO-1 in kidney [87]. Also, there exists an increase HO-1 expression in vascular smooth muscle cells exposed to the acidic medium ( $\mathrm{pH}$ 6.8) [88]. Our lab has previously demonstrated that, Ang II infusion promotes hypertension via induction of HO-1, which produces a marked increase in endogenous $\mathrm{CO}$, which elicit vasoconstriction by inhibiting nitric oxide synthase (NOS) [89]. Since, kidney proximal tubule has been implicated as a major site for heme synthesis [90], proximal tubule $\mathrm{HO}-1$ induction during metabolic acidosis may have possible influence to regulate sodium-linked acid-base transporters for sodium handling by the proximal tubule and eventual hypertension.

\subsection{Prostaglandins}

Prostaglandins (PGs) are recognized as intrarenal vasodilators which function as endocrine-antihypertensive agents during its existence in kidney [91]. PGE2, PGF2 $\alpha$ and PGA have been extensively studied for their role in regulating renal blood flow, electrolyte balance and essential hypertension [92]. PGA has been identified as a potential regulator of blood pressure homeostasis, as its concentration is seen to be reduced in hypertensive patients [93]. The effect of acute acidosis on prostaglandin levels was previously evaluated in rats, and the data revealed, serum PGF2 $\alpha$ is increased over eight minutes of time with the increase in degree of acidosis [94]. However, kidney being major site for metabolism of PGs [92], the renal mechanism of various PG isoforms on blood pressure regula- 
tion hasn't been studied much. Hence, acidosis-induced PG production in renal tissues can be a novel approach to examine the mechanism of acidosis induced hypertension. Since, PGA being the regulator of antihypertensive action and being itself metabolized in kidney cortex [95], the effect of chronic or acute metabolic acidosis, on levels of PGA might provide some ideas about its fate in renal tissues. Furthermore, an in vitro study suggests that, PGF2 $\alpha$ when subjected to LLC-PK1 cells of proximal tubule origin [96] in acidic condition, inhibits the ammonia production [97]. As we already discussed, ammonia metabolism is linked to sodium homeostasis and blood pressure regulation, the ultimate effect of PGF2 $\alpha$ can influence the renal mechanisms altering blood pressure.

Taken together, various local mediators of renal hemodynamics and metabolic functions can have important mechanistic link associated with acid-base imbalance and the hypertension (Figure 3 ). Hence, identification of specific mechanism could lead to novel insight to find the cause of hypertension.

\section{Conclusion}

Studies evaluating the role of a disturbance in acid-base balance leading to the pathogenesis of hypertension are scarce. The involvement of various sodium-dependent transporters in the kidney tubules specifically in the proximal tubule is responsible for the maintenance of normal concentrations of bicarbonates and the secretion of ammonia. Local production of Ang II, aldosterone, cortisol, prostaglandins and heme oxygenase in the kidney is a key regulator of these transporters. Hence, study of mechanisms involved in altered acid-base balance and their ability to promote an elevation in blood pressure could reveal novel therapeutic targets for the treatment of hypertension.

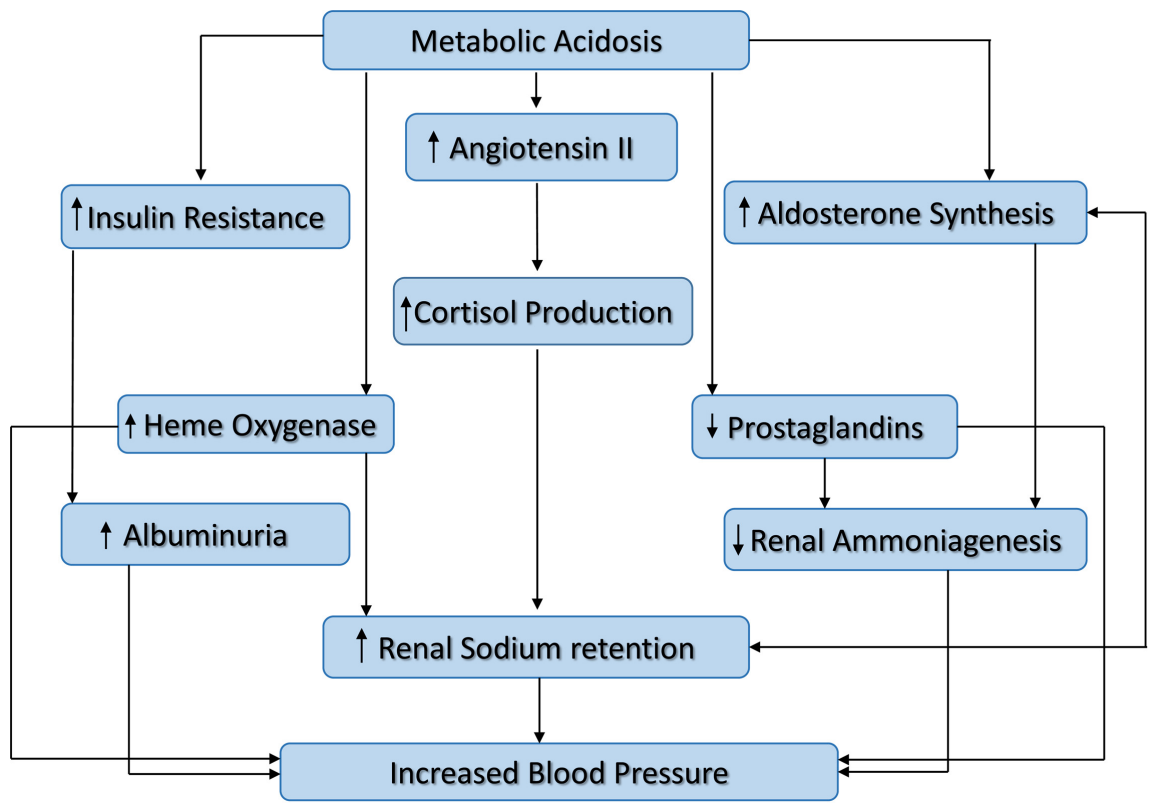

Figure 3. Possible linking mechanisms for the association between hypertension and metabolic acidosis. 


\section{Conflicts of Interest}

The authors declare no conflicts of interest.

\section{References}

[1] Van, B.J. and Inscho, E.W. (2015) Regulation of Renal Function and Blood Pressure Control by P2 Purinoceptors in the Kidney. Current Opinion in Pharmacology, 21, 82-88. https://doi.org/10.1016/j.coph.2015.01.003

[2] Hamm, L.L. and Simon, E.E. (1990) Ammonia Transport in the Proximal Tubule. Mineral Electrolyte Metabolism, 16, 283-290.

[3] Yim, H.E. and Yoo, K.H. (2008) Renin-Angiotensin System-Considerations for Hypertension and Kidney. Electrolyte and Blood Pressure Research, 6, 42-50. https://doi.org/10.5049/EBP.2008.6.1.42

[4] Giani, J.F., Janjulia, T., Taylor, B., Bernstein, E.A., Shah, K., Shen, X.Z., et al. (2014) Renal Generation of Angiotensin II and the Pathogenesis of Hypertension. Current Hypertension Reports, 16, 477. https://doi.org/10.1007/s11906-014-0477-1

[5] Nagami, G.T. and Kraut, J.A. (2010) Acid-Base Regulation of Angiotensin Receptors in the Kidney. Current Opinion in Nephrology and Hypertension, 19, 91-97. https://doi.org/10.1097/MNH.0b013e32833289fd

[6] Nagami, G.T., Chang, J.A., Plato, M.E. and Santamaria, R. (2008) Acid Loading in Vivo and Low pH in Culture Increase Angiotensin Receptor Expression: Enhanced Ammoniagenic Response to Angiotensin II. American Journal of Physiology-Renal Physiology, 6, 1864-1870. https://doi.org/10.1152/ajprenal.90410.2008

[7] Kobori, H., Nangaku, M., Navar, L.G. and Nishiyama, A. (2007) The Intrarenal Renin-Angiotensin System: From Physiology to the Pathobiology of Hypertension and Kidney Disease. Pharmacological Reviews, 59, 251-287. https://doi.org/10.1124/pr.59.3.3

[8] Saxena, P.R. (1992) Interaction between the Renin-Angiotensin-Aldosterone and Sympathetic Nervous Systems. Journal of Cardiovascular Pharmacology, 19, 80-88. https://doi.org/10.1097/00005344-199219006-00013

[9] Zimmerman, M.C., Lazartigues, E., Lang, J.A., Sinnayah, P., Ahmad, I.M., Spitz, D.R. and Davisson, R.L. (2002) Superoxide Mediates the Actions of Angiotensin II in the Central Nervous System. Circulation Research, 91, 1038-1045. https://doi.org/10.1161/01.RES.0000043501.47934.FA

[10] Satou R., Penrose, H. and Navar, L.G. (2018) Inflammation as a Regulator of the Renin-Angiotensin System and Blood Pressure. Current Hypertension Reports, 20, 100. https://doi.org/10.1007/s11906-018-0900-0

[11] Horita, S., Nakamura, M., Suzuki, M., Satoh, N., Suzuki, A., Homma, Y., et al. (2017) The Role of Renal Proximal Tubule Transport in the Regulation of Blood Pressure. Kidney Research and Clinical Practice, 36, 12-21. https://doi.org/10.23876/j.krcp.2017.36.1.12

[12] Boron, W.F. (2006) Acid-Base Transport by the Renal Proximal Tubule. Journal of American Society of Nephrology, 17, 2368-2382. https://doi.org/10.1681/ASN.2006060620

[13] Boedtkjer, E. and Aalkjaer, C. (2013) Disturbed Acid-Base Transport: An Emerging Cause of Hypertension. Frontiers in Physiology, 4, 388. https://doi.org/10.3389/fphys.2013.00388

[14] Ehret, G.B., Munroe, P.B., Rice, K.M., Bochud, M., Johnson, A.D., Chasman, D.I., et 
al. (2011) Genetic Variants in Novel Pathways Influence Blood Pressure and Cardiovascular Disease Risk. Nature, 478, 103-109. https://doi.org/10.1038/nature10405

[15] Boedtkjer, E., Praetorius, J., Matchkov, V.V., Stankevicius, E., Mogensen, S., Füchtbauer, A.C., et al., (2011) Disruption of $\mathrm{Na}^{+}-\mathrm{HCO}_{3}{ }^{-}$-Cotransporter $\mathrm{NBCn} 1$ (SLC4A7) Inhibits NO-Mediated Vasorelaxation, Smooth Muscle $\mathrm{Ca}^{2+}$-Sensitivity and Hypertension Development in Mice. Circulation, 124, 1819-1829.

https://doi.org/10.1161/CIRCULATIONAHA.110.015974

[16] Luft, F.C., Zemel, M.B., Sowers, J.A., Fineberg, N.S. and Weinberger, M.H. (1990) Sodium Bicarbonate and Sodium Chloride: Effects on Blood Pressure and Electrolyte Homeostasis in Normal and Hypertensive Man. Journal of Hypertension, 8, 663-670. https://doi.org/10.1097/00004872-199007000-00010

[17] Gröger, N., Vitzthum, H., Fröhlich, H., Krüger, M., Ehmke, H., Braun, T. and Boettger, T. (2012) Targeted Mutation of SLC4A5 Induces Arterial Hypertension and Renal Metabolic Acidosis. Human Molecular Genetics, 21, 1025-1036. https://doi.org/10.1093/hmg/ddr533

[18] Guyton, A.C. (1991) Blood Pressure Control-Special Role of the Kidneys and Body Fluids. Science, 252, 1813-1816. https://doi.org/10.1126/science.2063193

[19] Schultheis, P.J., Clarke, L.L., Meneton, P., Miller, M.L., Soleimani, M., et al. (1998) Renal and Intestinal Absorptive Defects in Mice Lacking the NHE3 $\mathrm{Na}^{+} / \mathrm{H}^{+} \mathrm{Ex}-$ changer. Nature Genetics, 19, 282-285. https://doi.org/10.1038/969

[20] Hamm, L.L., Nakhoul, N. and Hering-Smith, K.S. (2015) Acid-Base Homeostasis. Clinical Journal of American Society of Nephrology, 10, 2232-2242. https://doi.org/10.2215/CJN.07400715

[21] Valles, P., Wysocki, J. and Batlle, D. (2005) Angiotensin II and Renal Tubular Ion Transport. Scientific World Journal, 5, 680-690. https://doi.org/10.1100/tsw.2005.92

[22] Henger, A., Tutt, P., Riesen, W.F., Hulter, H.N. and Krapf, R. (2000) Acid-Base and Endocrine Effects of Aldosterone and Angiotensin II Inhibition in Metabolic Acidosis in Human Patients. Journal of Laboratory and Clinical Medicine, 136, 379-389. https://doi.org/10.1067/mlc.2000.110371

[23] Nagami, G.T. (2004) Ammonia Production and Secretion by S3 Proximal Tubule Segments from Acidotic Mice: Role of ANG II. American Journal of Physiology-Renal Physiology, 287, 707-712. https://doi.org/10.1152/ajprenal.00189.2003

[24] Nagami, G.T. (1995) Effect of Luminal Angiotensin II on Ammonia Production and Secretion by Mouse Proximal Tubules. American Journal of Physiology, 269, 86-92. https://doi.org/10.1152/ajprenal.1995.269.1.F86

[25] Wang, X., Armando, I., Upadhyay, K., Pascua, A. and Jose, P.A. (2009) The Regulation of Proximal Tubular Salt Transport in Hypertension: An Update. Current Opinion in Nephrology and Hypertension, 18, 412-420. https://doi.org/10.1097/MNH.0b013e32832f5775

[26] Baum, M., Twombley, K., Gattineni, J., Joseph, C., Wang, L., Zhang, Q., Dwarakanath, V., et al. (2012) Proximal Tubule $\mathrm{Na}^{+} / \mathrm{H}^{+}$Exchanger Activity in Adult NHE8-/-, NHE3-/-, and NHE3-/-/NHE8-/- Mice. American Journal of Physiology-Renal Physiology, 303, 1495-1502. https://doi.org/10.1152/ajprenal.00415.2012

[27] Li, H.C., Du, Z., Barone, S., Rubera, I., McDonough, A.A., Tauc, M., et al. (2013) Proximal Tubule Specific Knockout of the $\mathrm{Na}^{+} / \mathrm{H}^{+}$Exchanger NHE3: Effects on $\mathrm{Bi}-$ carbonate Absorption and Ammonium Excretion. Journal of Molecular Medicine, 91, 951-963. https://doi.org/10.1007/s00109-013-1015-3

[28] Noonan, W.T., Woo, A.L., Nieman, M.L., Prasad, V., Schultheis, P.J., Shull, G.E. and Lorenz, J.N. (2005) Blood Pressure Maintenance in NHE3-Deficient Mice with 
Transgenic Expression of NHE3 in Small Intestine. American Journal of Physiology-Regulatory Integrative and Comparative Physiology, 288, 685-691. https://doi.org/10.1152/ajpregu.00209.2004

[29] Li, X. and Zhuo, J.L. (2007) Selective Knockdown of AT1 Receptors by RNA Interference Inhibits Val5-ANG II Endocytosis and NHE-3 Expression in Immortalized Rabbit Proximal Tubule Cells. American Journal of Physiology-Cellular Physiology, 293, 367-378. https://doi.org/10.1152/ajpcell.00463.2006

[30] Seki, G., Coppola, S., Yoshitomi, K., Burckhardt, B.C., Samarzija, I., Müller-Berger, S. and Frömter, E. (1996) On the Mechanism of Bicarbonate Exit from Renal Proximal Tubular Cells. Kidney International, 49, 1671-1677. https://doi.org/10.1038/ki.1996.244

[31] Felder, R.A., Jose, P.A., Xu, P. and Gildea, J.J. (2016) The Renal Sodium Bicarbonate Cotransporter $\mathrm{NBCe}_{2}$ : Is It a Major Contributor to Sodium and $\mathrm{pH}$ Homeostasis? Current Hypertension Reports, 18, 71. https://doi.org/10.1007/s11906-016-0679-9

[32] Damkier, H.H., Nielsen, S. and Praetorius, J. (2007) Molecular Expression of SLC4-derived $\mathrm{Na}^{+}$-Dependent Anion Transporters in Selected Human Tissues. American Journal of Physiology-Regulatory Integrative and Comparative Physiology, 293, R2136-R2146. https://doi.org/10.1152/ajpregu.00356.2007

[33] Sonalker, P.A., Tofovic, S.P. and Jackson, E.K. (2004) Increased Expression of the Sodium Transporter BSC-1 in Spontaneously Hypertensive Rats. Journal of Pharmacological and Experimental Therapeutics, 311, 1052-1061. https://doi.org/10.1124/jpet.104.071209

[34] Wang, T. and Chan, Y.L. (1990) Mechanism of Angiotensin II Action on Proximal Tubular Transport. Journal of Pharmacological and Experimental Therapeutics, 252, 689-695.

[35] Chatsudthipong, V. and Chan, Y.L. (1991) Inhibitory Effect of Angiotensin II on Renal Tubular Transport. American Journal of Physiology-Renal Physiology, 260, F340-F346. https://doi.org/10.1152/ajprenal.1991.260.3.F340

[36] Liu, F.Y. and Cogan, M.G. (1990) Role of Protein Kinase C in Proximal Bicarbonate Absorption and Angiotensin Signaling. American Journal of Physiology, 258, F927-F933. https://doi.org/10.1152/ajprenal.1990.258.4.F927

[37] Liu, F.Y. and Cogan, M.G. (1989) Angiotensin II Stimulates Early Proximal Bicarbonate Absorption in the Rat by Decreasing Cyclic Adenosine Monophosphate. Journal of Clinical Investigation, 84, 83-91. https://doi.org/10.1172/JCI114174

[38] Alper, S.L. and Chernova, M.N. (2001) Stewart, A.K. Regulation of $\mathrm{Na}^{+}$-Independent $\mathrm{Cl}^{-} / \mathrm{HCO}_{3}^{-}$Exchangers by $\mathrm{pH}$. Journal of the Pancreas, 2, 171-175.

[39] Alper, S.L., Darman, R.B., Chernova, M.N. and Dahl, N.K. (2001) The AE Gene Family of $\mathrm{Cl} / \mathrm{HCO}_{3}^{-}$Exchangers. Journal of Nephrology, 15, S41-53.

[40] Alper, S.L. (2006) Molecular Physiology of SLC4 Anion Exchangers. Experimental Physiology, 91, 153-161. https://doi.org/10.1113/expphysiol.2005.031765

[41] Simao, S., Fraga, S., Jose, P.A. and Soares-da-Silva, P. (2008) Oxidative Stress and Alpha1-Adrenoceptor-Mediated Stimulation of the $\mathrm{Cl}^{-} / \mathrm{HCO}_{3}^{-}$Exchanger in Immortalized SHR Proximal Tubular Epithelial Cells. British Journal of Pharmacology, 153, 1445-1455. https://doi.org/10.1038/bjp.2008.16

[42] Pedrosa, R., Villar, V.A., Pascua, A.M., Simão, S., Hopfer, U., Jose, P.A. and Soares-da-Silva, P. (2008) $\mathrm{H}_{2} \mathrm{O}_{2}$ Stimulation of the $\mathrm{Cl}^{-} / \mathrm{HCO}_{3}^{-}$Exchanger by Angiotensin II and Angiotensin II Type 1 Receptor Distribution in Membrane Microdomains. Hypertension, 51, 1332-1338.

https://doi.org/10.1161/HYPERTENSIONAHA.107.102434 
[43] Stone, D.K., Seldin, D.W., Kokko, J.P. and Jacobson, H.R. (1983) Anion Dependence of Rabbit Medullary Collecting Duct Acidification. Journal of Clinical Investigation, 71, 1505-1508. https://doi.org/10.1172/JCI110905

[44] Doucet, A., Katz, A.I. and Morel, F. (1979) Determination of Na-K-ATPase Activity in Single Segments of the Mammalian Nephron. American Journal of Physiology, 237, F105-F113. https://doi.org/10.1152/ajprenal.1979.237.2.F105

[45] Katz, A.I. (1982) Renal Na-K-ATPase: Its Role in Tubular Sodium and Potassium Transport. American Journal of Physiology, 242, F207-F219. https://doi.org/10.1152/ajprenal.1982.242.3.F207

[46] Codina, J., Wall, S.M. and DuBose Jr., T.D. (1999) Contrasting Functional and Regulatory Profiles of the Renal $\mathrm{H}^{+}, \mathrm{K}^{+}$-ATPases. Seminars in Nephrology, 19, 399-404.

[47] Doucet, A. (1988) Function and Control of Na-K-ATPase in Single Nephron Segments of the Mammalian Kidney. Kidney International, 34, 749-760. https://doi.org/10.1038/ki.1988.245

[48] Massey, K.J., Li, Q., Rossi, N.F., Keezer, S.M., Mattingly, R.R. and Yingst, D.R. (2016) Phosphorylation of Rat Kidney Na-K Pump at Ser938 Is Required for Rapid Angiotensin II-Dependent Stimulation of Activity and Trafficking in Proximal Tubule Cells. American Journal of Physiology-Cellular Physiology, 310, C227-C232. https://doi.org/10.1152/ajpcell.00113.2015

[49] Rangel, L.B., Caruso-Neves, C., Lara, L.S. and Lopes, A.G. (2002) Angiotensin II Stimulates Renal Proximal Tubule $\mathrm{Na}^{+}$-ATPase Activity through the Activation of Protein Kinase C. Biochimica et Biophysica Acta, 1564, 310-316. https://doi.org/10.1016/S0005-2736(02)00472-8

[50] White, C.N., Figtree, G.A., Liu, C.C., Garcia, A., Hamilton, E.J., Chia, K.K. and Rasmussen, H.H. (2009) Angiotensin II Inhibits the $\mathrm{Na}^{+}-\mathrm{K}^{+}$Pump via PKC-Dependent Activation of NADPH Oxidase. American Journal of Physiology-Cellular Physiology, 296, C693-C700. https://doi.org/10.1152/ajpcell.00648.2008

[51] Salyer, S.A., Parks, J., Barati, M.T., Lederer, E.D., Clark, B.J., Klein, J.D., et al. (2013) Aldosterone regulates $\mathrm{Na}^{+}, \mathrm{K}^{+}$ATPase Activity in Human Renal Proximal Tubule Cells through Mineralocorticoid Receptor. Biochimica et Biophysica Acta, 1833, 2143-2152. https://doi.org/10.1016/j.bbamcr.2013.05.009

[52] Herman, M.B., Rajkhowa, T., Cutuli, F., Springate, J.E. and Taub, M. (2010) Regulation of Renal Proximal Tubule Na-K-ATPase by Prostaglandins. American Journal of Physiology-Renal Physiology, 298, F1222-F1234. https://doi.org/10.1152/ajprenal.00467.2009

[53] Nagami, G.T. (2008) Role of Angiotensin II in the Enhancement of Ammonia Production and Secretion by the Proximal Tubule in Metabolic Acidosis. American Journal of Physiology-Renal Physiology, 294, F874-F880. https://doi.org/10.1152/ajprenal.00286.2007

[54] Weiner, I.D. and Verlander, J.W. (2017) Ammonia Transporters and Their Role in Acid-Base Balance. Physiological Reviews, 97, 465-494. https://doi.org/10.1152/physrev.00011.2016

[55] Chobanian, M.C. and Julin, C.M. (1991) Angiotensin II Stimulates Ammoniagenesis in Canine Renal Proximal Tubule Segments. American Journal of Physiology, 260, F19-F26. https://doi.org/10.1152/ajprenal.1991.260.1.F19

[56] Nagami, G.T. (1990) Ammonia Production and Secretion by Isolated Perfused Proximal Tubule Segments. Mineral Electrolyte Metabolism, 16, 259-263.

[57] Nagami, G.T. (1992) Effect of Angiotensin II on Ammonia Production and Secretion by Mouse Proximal Tubules Perfused in Vitro. Journal of Clinical Investiga- 
tion, 89, 925-931. https://doi.org/10.1172/JCI115673

[58] Weiner, I.D. and Verlander, J.W. (2013) Renal Ammonia Metabolism and Transport. Comparative Physiology, 3, 201-220. https://doi.org/10.1002/cphy.c120010

[59] Weiner, I.D. and Hamm, L.L. (2007) Molecular Mechanisms of Renal Ammonia Transport. Annual Review in Physiology, 69, 317-340. https://doi.org/10.1146/annurev.physiol.69.040705.142215

[60] Carnauba, R.A., Baptistella, A.B., Paschoal, V. and Hübscher, G.H. (2017) Diet-Induced Low-Grade Metabolic Acidosis and Clinical Outcomes: A Review. $\mathrm{Nu}$ trients, 9, E538. https://doi.org/10.3390/nu9060538

[61] Adeva, M.M. and Souto, G. (2011) Diet-Induced Metabolic Acidosis. Clinical Nutrition, 30, 416-421. https://doi.org/10.1016/j.clnu.2011.03.008

[62] Farber, M.O., Szwed, J.J., Dowell, A.R. and Strawbridge, R.A. (1976) The Acute Effects of Respiratory and Metabolic Acidosis on Renal Function in the Dog. Clinical Science and Molecular Medicine, 50, 165-169. https://doi.org/10.1042/cs0500165

[63] Ng, H.Y., Chen, H.C., Tsai, Y.C., Yang, Y.K. and Lee, C.T. (2011) Activation of Intrarenal Renin-Angiotensin System during Metabolic Acidosis. American Journal of Nephrology, 34, 55-63. https://doi.org/10.1159/000328742

[64] Aalkjaer, C. and Mulvany, M.J. (1988) Effect of Changes in Intracellular pH on the Contractility of Rat Resistance Vessels. Progress in Biochemical Pharmacology, 23, 150-158.

[65] Aalkjaer, C. and Mulvany, M.J. (1991) Steady-State Effects of Arginine Vasopressin on Force and pHi of Isolated Mesenteric Resistance Arteries from Rats. American Journal of Physiology, 261, C1010-C1017. https://doi.org/10.1152/ajpcell.1991.261.6.C1010

[66] Boedtkjer, E., Praetorius, J. and Aalkjaer, C. (2006) NBCn1 (SLC4A7) Mediates the $\mathrm{Na}^{+}$-Dependent Bicarbonate Transport Important for Regulation of Intracellular pH in Mouse Vascular Smooth Muscle Cells. Circulation Research, 98, 515-523. https://doi.org/10.1161/01.RES.0000204750.04971.76

[67] Danielsen, A.A., Parker, M.D., Lee, S., Boron, W.F., Aalkjaer, C. and Boedtkjer, E. (2013) Splice Cassette II of $\mathrm{Na}^{+}-\mathrm{HCO}_{3}^{-}$Cotransporter NBCn1 (SLC4A7) Interacts with Calcineurin A: Implications for Transporter Activity and Intracellular $\mathrm{pH}$ Control during Rat Artery Contractions. Journal of Biological Chemistry, 288, 8146-8155. https://doi.org/10.1074/jbc.M113.455386

[68] Freeman, A.M. and Pennings, N. (2019) Insulin Resistance. In: StatPearls [Internet], StatPearls Publishing, Treasure Island (FL), Las Vegas, NV.

[69] Artunc, F., Schleicher, E., Weigert, C., Fritsche, A., Stefan, N. and Häring, H.U. (2016) The Impact of Insulin Resistance on the Kidney and Vasculature. Nature Review Nephrology, 12, 721-737. https://doi.org/10.1038/nrneph.2016.145

[70] Salvetti, A., Brogi, G., Di Legge, V. and Bernini, G.P. (1993) The Inter-Relationship between Insulin Resistance and Hypertension. Drugs, 46, 149-159. https://doi.org/10.2165/00003495-199300462-00024

[71] DeFronzo, R.A. and Beckles, A.D. (1979) Glucose Intolerance Following Chronic Metabolic Acidosis in man. American Journal of Physiology, 236, E328-E334. https://doi.org/10.1152/ajpendo.1979.236.4.E328

[72] Bellasi, A., Micco, L.D., Santoro, D., Marzocco, S., Simone, E.D., et al. (2016) Correction of Metabolic Acidosis Improves Insulin Resistance in Chronic Kidney Disease. BMC Nephrology, 17, 158. https://doi.org/10.1186/s12882-016-0372-x 
[73] Souto, G., Donapetry, C., Calvino, J. and Adeva, M.M. (2011) Metabolic Acidosis-Induced Insulin Resistance and Cardiovascular Risk. Metabolic Syndrome and Related Disorders, 9, 247-253. https://doi.org/10.1089/met.2010.0108

[74] Kumari, M., Sharma, R., Pandey, G., Ecelbarger, C.M., Mishra, P. and Tiwari, S. (2019) Deletion of Insulin Receptor in the Proximal Tubule and Fasting Augment Albumin Excretion. Journal of Cellular Biochemistry, 120, 10688-10696. https://doi.org/10.1002/jcb.28359

[75] Zhou, M.S., Schulman, I.H. and Zeng, Q. (2012) Link between the Renin-Angiotensin System and Insulin Resistance: Implications for Cardiovascular Disease. Vascular Medicine, 17, 330-341. https://doi.org/10.1177/1358863X12450094

[76] Guagliardo, N.A., Yao, J., Bayliss, D.A. and Barrett, P.Q. (2011) TASK Channels Are Not Required to Mount an Aldosterone Secretory Response to Metabolic Acidosis in Mice. Molecular and Cellular Endocrinology, 336, 47-52. https://doi.org/10.1016/j.mce.2010.11.017

[77] Mitsuuchi, Y., Kawamoto, T., Naiki, Y., Miyahara, K., Toda, K., Kuribayashi., et al. (1992) Congenitally Defective Aldosterone Biosynthesis in Humans: The Involvement of Point Mutations of the P-450C18 Gene (CYP11B2) in CMO II Deficient Patients. Biochemical and Biophysical Research Communications, 182, 974-979. https://doi.org/10.1016/0006-291X(92)91827-D

[78] Schambelan, M., Sebastian, A., Katuna, B.A. and Arteaga, E. (1987) Adrenocortical Hormone Secretory Response to Chronic NH4Cl-Induced Metabolic Acidosis. American Journal of Physiology, 252, E454-E460. https://doi.org/10.1152/ajpendo.1987.252.4.E454

[79] Wagner, C.A. (2014) Effect of Mineralocorticoids on Acid-Base Balance. Nephron Physiology, 128, 26-34. https://doi.org/10.1159/000368266

[80] Hulter, H.N., Ilnicki, L.P., Harbottle, J.A. and Sebastian, A. (1977) Impaired Renal $\mathrm{H}^{+}$Secretion and NH3 Production in Mineralocorticoid-Deficient Glucocorticoid-Replete Dogs. American Journal of Physiology, 232, 136-146. https://doi.org/10.1152/ajprenal.1977.232.2.F136

[81] Murakami, K., Sasaki, S., Takahashi, Y. and Uenishi, K. (2008) Japan Dietetic Students' Study for Nutrition and Biomarkers Group. Association between Dietary Acid-Base Load and Cardiometabolic Risk Factors in Young Japanese Women. British Journal of Nutrition, 100, 642-651. https://doi.org/10.1017/S0007114508901288

[82] Ferrari, P. (2003) Cortisol and the Renal Handling of Electrolytes: Role in Glucocorticoid-Induced Hypertension and Bone Disease. Best Practical Research in Clinical Endocrinology and Metabolism, 17, 575-589. https://doi.org/10.1016/S1521-690X(03)00053-8

[83] Hamm, L.L., Ambühl, P.M. and Alpern, R.J. (1999) Role of Glucocorticoids in Acidosis. American Journal of Kidney Diseases, 34, 960-965. https://doi.org/10.1016/S0272-6386(99)70059-4

[84] Whitworth, J.A., Williamson, P.M., Mangos, G. and Kelly. J.J. (2005) Cardiovascular Consequences of Cortisol Excess. Vascular Health Risk Management, 1, 291-299. https://doi.org/10.2147/vhrm.2005.1.4.291

[85] Jackson, K.E., Jackson, D.W., Quadri, S., Reitzell, M.J. and Navar, L.G. (2011) Inhibition of Heme Oxygenase Augments Tubular Sodium Reabsorption. American Journal of Physiology-Renal Physiology, 300, F941-F946. https://doi.org/10.1152/ajprenal.00024.2010 
[86] Elbirt, K. and Bonkovsky, H. (1999) Heme Oxygenase: Recent Advances in Understanding Its Regulation and Role. Proceedings of the Association of American Physicians, 111, 438-447. https://doi.org/10.1111/paa.1999.111.5.438

[87] Magalhães, P.A., de Brito, T.S., Freire, R.S., da Silva, M.T., dos Santos, A.A., Vale, M.L., et al. (2016) Metabolic Acidosis Aggravates Experimental Acute Kidney Injury. Life Sciences, 146, 58-65. https://doi.org/10.1016/j.lfs.2016.01.007

[88] Christou, H., Bailey, N., Kluger, M.S., Mitsialis, S.A. and Kourembanas, S. (2005) Extracellular Acidosis Induces Heme Oxygenase-1 Expression in Vascular Smooth Muscle Cells. American Journal of Physiology Heart Circulation Physiology, 288, H2647-2652. https://doi.org/10.1152/ajpheart.00937.2004

[89] Quadri, S., Prathipati, P., Jackson, D.W. and Jackson, K.E. (2013) Augmentation of Heme Oxygenase Promotes Acute Angiotensin II Induced Hypertension. Clinical and Experimental Medical Sciences, 1, 21-43.

https://doi.org/10.12988/cems.2013.13003

[90] Tracz, M.J., Alam, J. and Nath, K.A. (2007) Physiology and Pathophysiology of Heme: Implications for Kidney Disease. Journal of American Society of Nephrology, 18, 414-420. https://doi.org/10.12988/cems.2013.13003

[91] Lee, J.B., Patak, R.V. and Mookerjee, B.K. (1976) Renal Prostaglandins and the Regulation of Blood Pressure and Sodium and Water Homeostasis. American Journal of Medicine, 60, 798-816. https://doi.org/10.1016/0002-9343(76)90893-7

[92] Sun, F.F., Taylor, B.M., Mcguire, J.C. and Wong, P.Y.K. (1981) Metabolism of Prostaglandins in the Kidney. Kidney International, 19, 760-770. https://doi.org/10.1038/ki.1981.78

[93] Lee, J.B. and Attallah, A.A. (1975) Renal Prostaglandins. Nephron, 15, 350-368. https://doi.org/10.1159/000180520

[94] Bolam, D.L., Leuschen, M.P. and Nelson Jr., R.M. (1983) Prostaglandin Levels Following Acute Metabolic Acidosis. Prostaglandins Leukotrienes and Medicine, 12, 381-383. https://doi.org/10.1016/0262-1746(83)90028-8

[95] Attallah, A.A., Payakkapan, W. and Lee, J.B. (1974) Metabolism of Prostaglandin A: 1. The Kidney Cortex as a Major Site of PGA2 Degradation. Life Sciences, 14, 1521-1534. https://doi.org/10.1016/0024-3205(74)90163-5

[96] Nielsen, R., Birn, H., Moestrup, S.K., Nielsen, M., Verroust, P. and Christensen, E.I. (1998) Characterization of a Kidney Proximal Tubule Cell Line, LLC-PK1, Expressing Endocytotic Active Megalin. Journal of the American Society of Nephrology, 10, 1767-1776.

[97] Sahai, A., Goyal, M. and Tannen, R.L. (1990) Prostaglandin F2 Alpha Inhibits the Ammoniagenic Response to Acute Acidosis in LLC-PK1 Cells. Journal of the American Society of Nephrology, 1, 882-889. 